\title{
The Phenomenology of Near-Death Consciousness in Past-Life Regression Therapy: A Pilot Study
}

\author{
Jenny Wade, Ph.D. \\ Ross, $C A$
}

ABSTRACT. Although past-life regression therapy has not been shown to be the re-experiencing of a verifiable previous biological existence, therapists have noted similarities between the phenomenology of post-death awareness reported by regressed subjects and the phenomenology of near-death experiences (NDEs). This paper reports the results of a pilot study exploring those similarities as far as the therapeutic modality normally accommodates post-death phenomena. Similarities and differences between NDEs and postdeath regression phenomena suggest new avenues of research.

"Past-life regression" in Western usage describes the emergence of impressions, images and sensations that seem to be memories of an earlier existence, usually occurring during special, evocative circumstances, such as psychotherapy. The term has evolved from a technology originated by Albert de Rochas, a French hypnotherapist at the turn of the century (Christie-Murray, 1981). Although the spontaneous recollection of apparent past-life memories by children is well documented in cultures that accept reincarnation (Stevenson, $1975-80,1980,1987)$, most Western literature concerns recollections produced by adults in altered states of consciousness. The largest body comes from therapeutic modalities involving the deeper layers of the psyche, such as traditional psychoanalysis; Rolfing, accupressure and other body work; rebirthing; sensory isolation; controlled drug therapy; and hypnosis (Bache, 1990). Like age regression ther-

Jenny Wade, Ph.D., is a management consultant in private practice who lectures on noetics and developmental psychology. Reprint requests should be addressed to Dr. Wade at P.O. Box 571, Ross, CA 94957. 
apy, the systematic regressing of patients to produce past-life stories has proven unusually efficacious in the treatment of certain psychological and psychosomatic conditions (Carfaro, 1986; Cladder, 1986; Hull, 1984; Marriott, 1984; Nash, 1992; Netherton and Shiffrin, 1978; Schlotterbeck, 1987).

Although numerous attempts have been made to verify past-life recollections as having come from historical individuals, the data are inconclusive (Rogo, 1985; Stevenson, 1975-80; Wilson, 1982). The apparently universal ability to recall material that seems to represent a previous biological existence is independent of the consciously held beliefs of either patient or therapist; in fact, it often contradicts them (Bache, 1990; Christie-Murray, 1981; TenDam, 1990). Furthermore, many patients who have undergone past-life therapy are reluctant to characterize their regression experiences as histories of biological past lives, even if they believe in reincarnation.

Most contemporary regression therapy involves altered states of consciousness that are a part of the therapeutic modality itself, especially the use of deep relaxation or hypnosis, to facilitate access to past-life stories (Wambach, 1978, 1981; Weiss, 1988; Woolger, 1987, 1988). The therapist typically guides the subject through a past-life history, concentrating on incidents carrying a strong emotional charge, especially the circumstances surrounding the death of the regressed persona. In some of the earliest published contemporary accounts, before information about near-death experiences (NDEs) was widely known, regressed subjects spontaneously reported altered states associated with death, especially out-of-body experiences (OBEs) (Fiore, 1978; Netherton and Shiffrin, 1978). Regression therapists have become familiar with this phenomenon, noting its resemblance to NDEs (Grof, 1985; Woolger, 1988). But many, if not most, therapy patients are naive in this respect. The following report by a male subject recalling life as a woman in 1920s New York is fairly typical:

"I'm quite sick and old now. It is pneumonia. I know I am going to die soon. So do [the family]. They're all there. . . . They don't give a damn. Making nice noises. They can't wait for me to go. ... Oh, my chest, I can't breathe. . . It hurts. . . I'm very weak. I'm going now." Convulsions, coughing, then he goes quite limp on the couch.

"What happened?" [the therapist asks].

"I'm not there anymore. I seem to have floated above my body. I'm not in it now, no more breathing. Thank God that's over! . . . There, Minny's crying, but she was always sentimental. She didn't care about me any more than the rest. Well, I'm leaving now. It's begin- 
ning to seem very far away. I'm floating off somewhere else." (Woolger, 1988, pp. 282-283)

After having re-lived biographical events, the subject is usually guided through the past-life personality's last breath and then asked to reflect upon the circumstances and unfinished business of that life. Many therapists then direct their subjects to a place from which patients can compare the past-life biography with their present situation ("real life"), looking for patterns, connections, and relationships (Oppenheim, 1986).

Although past-life therapists have observed similarities between their patients' out-of-body, post-death descriptions and NDE accounts (Wambach, 1986; Woolger, 1988), no systematic study has been conducted of the post-death states in past-life regression, nor has any systematic comparison of those states been made with NDEs.

The focus of this pilot study is to examine how people experience after-death consciousness during past-life regression and to compare the phenomenology of that state with the phenomenology reported in the near-death literature by people who have apparently died and been resuscitated. Of the various stages of near-death experience identified by Kenneth Ring (1980), this comparison is limited to the out-of-body mode when the seemingly deceased person's awareness leaves the body and experiences events in the here-and-now from a remote vantage point, usually, but not always, in the vicinity of the body.

There are several good reasons for narrowing the scope of this project to the out-of-body phase of the experience. First, in the neardeath literature, this experience appears to be the least influenced by cultural or personal beliefs because people are usually reporting events in ordinary life, such as watching rescue workers operate on their bodies, not visions of other worlds or otherworldly beings. Indeed, many memories survivors have of the events they observed have been independently validated by family members and medical personnel (Ring and Lawrence, 1993; Sabom, 1982). The other reasons for examining the out-of-body phase concern the dynamics of regression therapy and are based on the spontaneous quality of the experience. Significantly, an out-of-body experience occurs in the absence of any prompting by the therapist after the regression persona "dies"; this is an important qualification, since certain aspects of the altered states employed in therapy render the subject highly suggestible. Furthermore, although a few regression subjects also spon- 
taneously report experiences that resemble other phases of the NDE, such as the tunnel, encounters with predeceased relatives, and meetings with otherworldly figures, little information on these experiences is available because post-death phenomena in themselves are incidental to the therapeutic process, and therefore, are seldom explored. And finally, aside from the tendency for cultural bias to appear in otherworldly experiences in NDEs (Zaleski, 1987), information about otherworldly experiences in regressions was excluded because the way in which therapists guide clients beyond the immediate death experience is usually too suggestive to represent a spontaneous event for the subject (for example, "imagine yourself on a summit from which you can see the events of this past life and your current life spread out before you," or "go now to a higher plane").

Before exploring the out-of-body state described in regressions, I offer for comparison a review of the salient NDE phenomenology. In addition to person, place, and time, the three clinical "spheres of orientation" essential to any conscious experience, cognitive and emotional aspects may characterize a particular state. These dimensions are fundamental to phenomenological studies. In the case of NDEs, as the dying individual's consciousness changes from fear and trauma, he or she initially enjoys an extremely positive emotional experience characterized by an unusual sense of peace, joy and wellbeing (Greyson, 1985; Moody, 1975; Ring, 1980). Fear and pain associated with the body and the struggle to live vanish. Throughout the passage to the disembodied state, people report no discontinuity of awareness or sense of self, and may not be aware that they are dead until some living person announces that fact. Raymond Moody (1975) reported a wide range of emotions prior to, and in response to, this information, such as a desperate desire to get back into the body, concern about the state of the body, and regarding the body as unfamiliar, but Ring, in a more rigorous study, did not find these negative affects (1980). Most of Ring's respondents seemed to have a rather indifferent and matter-of-fact attitude toward their bodies, as illustrated in the published transcripts of their accounts.

According to the near-death literature, out-of-body visual and auditory perception seems to be normal or even enhanced to great clarity (Moody, 1975; Ring, 1980, 1984). Experiences that seem auditory may not be exactly the same as sensory impressions processed through the ear and cochlear nerve but may arise from some analogous source "felt" to be like hearing, since survivors of near-death experiences also often display veridical, telepathic knowledge of the unspoken 
thoughts of the living people present. The same may be true of visual impressions, as well (Ring and Cooper, 1997). The vantage point for visual impressions often seems to be in the air somewhat above the events taking place around the body, and looking down. Experiences of taste and smell seldom appear in near-death narratives.

Kinesthetic impressions are highly unusual in the disembodied state. NDE survivors describe themselves as light or weightless and floating, but the form they assume has been variously reported: no form, or disembodied, pure awareness; an amorphous or spherical shape; or an insubstantial but human form (Moody, 1975; Ring, 1980, 1984). If they possess shape, people use terms such as mist, clouds, smoke, vapors, and the like to describe their form (Moody, 1975). Their insubstantial nature prevents their making a solid, tactile contact with material objects, so that their hands seem to pass through the loved ones they try to touch and so that they can entirely pass through solid barriers, such as walls. Furthermore, some survivors report being able to "think" themselves through space to a remote location (Moody, 1975, 1977; Ring, 1980, 1984; Zaleski, 1987).

Mentation seems to be clear and rational, but spatiotemporal perception is somewhat altered (Moody, 1975; Ring, 1980, 1984). Survivors remark that the out-of-body state has a sense of timelessness, even though events are experienced sequentially (Carr, 1993; Ring, 1980). A minority report that time seems either slower or faster than normal. Although some spatial constructs, such as the solidity of material objects, may be experienced in a different way, perception nevertheless seems to conform to the usual three-dimensional spatiality reliant on persistence in time. Places may be experienced in a directional sequence but possess an unclear expanse or have an indeterminate distance between them (Carr, 1993).

Turning now to past-life regressions, any phenomenological study of an altered state nested in another altered state is complex. Therapeutic past-life regressions usually occur during nonordinary states featuring higher alpha electroencephalographic (EEG) activity and more right-hemisphere activity than normal waking consciousness, such as light trance, deep relaxation, or hypnosis, which are associated with greater visual imagery and a diminished or distorted sense of the passage of time, compared to ordinary (beta) awareness. Just as normal waking consciousness is presumed to be the baseline for comparison of after-death modes in NDEs, alterations in phenomenology during the regression, experienced by the subject as different modes of consciousness, are treated in relative terms as they differ 
from the baseline nonordinary state initiated to access the past life story. The distinctiveness of these modes is not only experienced by the subject, but is obvious to the therapist, as well, in keeping with Charles Tart's definition of discrete states of consciousness (1983). No attempt is being made here to qualify the altered state that provides the fundamental or baseline mode of awareness used to access the story. This baseline mode is presumed to be more or less responsive to the therapist's suggestion, to have slightly altered sensory impressions, such as greater visualization and less verbalization, and bodily sensations in the absence of external stimuli, but otherwise to function within a perceptual field delimited by the familiar experience of three-dimensional space and historical time.

\section{Methodology}

This pilot study attempted to elucidate the impressions of therapists and the inferences from regression transcripts that subjects spontaneously experience something like the out-of-body phase of an NDE during the death of their past-life persona. The technique used was face-to-face interviews employing a structured protocol of openended questions concerning the subject's memory (in a normal state) of the phenomena experienced after death during past-life regressions. Questions did not address the content of any regression experience other than the experience of time, space, personal agency, sensory impressions, the quality of affect and cognition. The expectation that a person can remember an altered-state experience such as an NDE or a past-life regression while in a normal state of consciousness is reasonable, but with qualifications. Although many phenomenological aspects are ineffable or cannot be translated from one state to the next without significant distortion (the difference between recalling a dream when awake and experiencing the dream during sleep, for example), a long tradition of research supports the notion that subjects can reliably describe such states with sufficient detail to map their salient features (Siegel, 1977; Tart, 1983).

Nine adult volunteers, two men and seven women, were selected by referral from a regression therapist. Their ages ranged from 34 to 53. All were college-educated Caucasians, and most had done some work at the graduate level. All had experienced altered states other than past-life regression, including the ingestion of alcohol or drugs, meditation, body-work and breath-work. None had had an 
NDE, and only two expressed any familiarity with near-death phenomena. Each participant had undergone multiple regressions, ranging from four to approximately 20 past-life sessions. All subjects had had more than one past-life experience in a therapeutic setting within the past year, most with the referring clinician, but three had undergone regression treatment with other practitioners. The techniques used to induce regressions were typically deep relaxation and autosuggestion.

All participants had been raised in a Christian tradition but, except for two Episcopalians, no longer identified themselves with a particular sect or religion. Although they all expressed some belief in the possibility of reincarnation, they were unanimous in saying they were neither certain that an actual past life was being re-experienced during regression therapy, nor did they believe actual reexperiencing of a past life was necessary. They indicated that regression material might be unconscious projection, as the following statements show:

I'm not really sure. There are times when I have doubted what it is, that it is a past life. I do believe in reincarnation, always have, even as a child .... I don't try to determine what it is. I just look at what I have to learn ... and if it's ... my subconscious creating stories to explain what's bothering it, then I don't worry about it. If I choose to believe in past lives, that's okay, too. (Subject 3)

Personally I believe in past lives, but I can't really say whether or not in a particular regression I'm really going into a past life, or I'm tapping into a collective conscious [sic] experience, memory, or metaphor, or story that appears to me to help me understand some complex I'm playing out in this life or something I need to be aware of. I can't say that particular experience is a past life. I don't know. I'm really okay with calling it imagination. It doesn't have to be anything. I can call it a metaphor if it helps me understand myself better and leave it at that, but that doesn't mean I don't believe in past life. (Subject 9)

\section{Results}

The participants indicated that the subjective experience of awareness immediately following the death of the past-life personality was qualitatively distinct from the way they experienced "being in the past life." The primary shift occurred as a detachment from the body 
and personality of the dead self. It was experienced as an abrupt transition from the living state.

Transition out of the body was signaled by instant relief from bodily sensations. Since regressed subjects typically suffer acutely at the time of death, usually with real-time symptoms physically obvious to the therapist, their passage from experiencing self within the body of the past-life personality to an exterior locus marked the immediate cessation of the physical pain they were feeling. Furthermore, emotional involvement and self-identification with the deceased personality also diminished as the point of view shifted from that of actor to observer, as I will discuss in more detail below:

At death your feelings are not connected with the body. If there's a split of any kind, it's that you don't feel the body, the pains .... [It's] as if you're watching a movie or something .... [You] shift to a more observational experience, like looking at the body as a movie or something outside yourself. (Subject 1)

I'm not particularly aware of sensations [after death], no feelings, whereas when I was in my [regressed personality] body I was having sensations of being hit or pulled or being struck. . . . (Subject 3)

The relief from physical sensation was coupled with a sense of emotional peace, although the euphoria reported by NDE survivors seemed to be lacking:

At the point of death, the emotions shut off like turning a light switch .... Sometimes at the moment of death the emotions are very intense, but . . it all shuts off . . . and I leave all those feelings behind. (Subject 8)

Generally, it's . . . relief from suffering. I haven't done a regression where I died in my sleep, and most of the regressions involve very painful lives and even more painful deaths .... In the after-death state, the pain is gone, you know it's over, and in some cases it's like walking out of a stadium after your team lost the ball game. There's nothing you can do about it, you're pretty much resigned to it, but you're free of the pain. (Subject 2)

Exactly how the transition to an outside point-of-view occurred differed considerably, paralleling the variety shown in NDE records. Some experienced themselves rising, others were just "out." Subjects found themselves in the vicinity of the corpse, usually above it. Perceptions of distance from the body differed across participants and even across the various regressions recalled by single individuals, ranging from "right next to" the body to as much as 100 feet above 
it or even "in space." Varying distance is also reported in NDE accounts (Ring, 1980).

Descriptions of the after-death self entity were inconsistent, just as in the NDE literature. Five described their after-death self as lacking a body, although they were aware of location at a particular point in space. Hans TenDam suggested that these forms may be "psychoplastic," or shaped by the subject's ideas of how the self is experienced, after Robert Crookall (TenDam, 1990). In general, subjects reported that they were physically unconfined, floating, and weightless; however, four also reported some sense of shape:

I'm everywhere and nowhere, a real nebulous feeling. A couple of times I've had the sensation of floating above and that's usually when I've been more emotionally attached to the body . . . . It's like I'm a bunch of atoms floating above, dissipating. It's because [the therapist] would give this suggestion that you're above the body looking down. It seems that if he doesn't reinforce that sensation of being above, the body dissipates and I'm a bunch of atoms dissipating, everywhere and nowhere. (Subject 4)

Well, it's like I'm in a spiritual body that nobody could see, but there's containment of me as a spiritual being. I'm not just floating out there as an amorphous body. It's like a location in space, and I may be aware of my head [butl I'm not aware of my arms .... (Subject 2)

Body, no. Form, yes. An energy form, not a structure . . . I don't feel like I'm diffuse energy, but an energy structure . . . a dense form of energy, as opposed to energy flowing, some location in space. (Subject 3)

None of the subjects was aware of any connection linking the after-death source of awareness to the body of the regressed personality, such as a silver cord, in keeping with Ring's research (1980). During the interview, two logically deduced that because they seemed to have location in space and had experienced a sense of movement they must have had mass, but this reasoning was clearly not a part of their regression experience. A majority remarked on the sense of freedom being out of the body afforded. They cited a strong sense of potential for movement, particularly the ability to relocate by "thinking themselves" into a different place rather than having to employ physical means of locomotion. This potential was reported as an impression only; no subjects reported having tested it by actually moving to another location. 
In contrast to the majority of NDE reports of heightened perception, regression subjects said that their sensory field was noticeably reduced from the level of awareness they had experienced (in the therapeutic altered state) as the "living" regressed personality. For many, information in this after-death mode was obtained only visually or intuitively as an overall impression. Auditory, tactile, olfactory and somatic sensations, which had often been pronounced as the past life was re-experienced, dropped away at death.

Moreover, perceptions of time and space were significantly altered. As opposed to the experience of linear time during the regressed life, awareness of past and future seemed to vanish at death, leaving the present. Everything was "now," in the moment. Events were, however, reported sequentially. Objects within the perceptual field tended to retain their spatial boundaries, but respondents indicated a sense of infinite space spreading out in all directions, particularly upward without horizon, as if they were on a cusp between a bounded and a limitless world. This sense of infinite space has been reported by a minority of NDE survivors (Ring, 1980).

Table 1 depicts salient features of the spatiotemporal aspects of the physical world experience during the life of the regressed persona, contrasted with the after-death experience in the regression. Both are compared to the phenomenology of the out-of-body state reported by NDE survivors.

The experience of self was continuous for regression subjects, even though the locus of awareness was displaced out of the body and altered from the usual spatiotemporality. This continuity of selfawareness is quite complex, however, and very different from what happens to the sense of self in NDEs. In NDEs, survivors report no break in the continuity of their self-awareness when moving from inside the dying body to an out-of-body location. The body, regarded as a vehicle needed for earthly life, is frequently the object of emotion in near-death experiences, such as repugnance at the coarseness of material form, compassion or wonder at a discarded form, or desperate desire to re-enter the form. Near-death survivors experience themselves as the same person in death as in life; there is no radical change of personality structure. Regression subjects, on the other hand, report having changed both form and personality. Upon moving out of the body, the after-death self regarded the form as inconsequential and the personality that had occupied it as sufficiently alien to be viewed with critical detachment. The experienced personality shift reduced the former persona to a subpersonality wholly owned, 


\section{Table 1}

\section{Physical Experience in Life and Death in Past-Life Regression and in the NDE Out-of-Body State}

\begin{tabular}{|c|c|c|c|}
\hline & $\begin{array}{c}\text { Regressed } \\
\text { Personality } \\
\text { When Living }\end{array}$ & $\begin{array}{l}\text { Regressed } \\
\text { Post-Death } \\
\text { Self }\end{array}$ & $\begin{array}{c}\text { NDE } \\
\text { Post-Death } \\
\text { Self }\end{array}$ \\
\hline Time & Historical, linear & $\begin{array}{l}\text { Timeless present, } \\
\text { yet events are } \\
\text { sequential }\end{array}$ & $\begin{array}{l}\text { Timeless present, } \\
\text { yet events are } \\
\text { sequential }\end{array}$ \\
\hline Space & Three-dimensional & $\begin{array}{l}\text { Access to infinite } \\
\text { space and three- } \\
\text { dimensional realm } \\
\text { (a border?) }\end{array}$ & $\begin{array}{l}\text { Three-dimensional } \\
\text { realm; minority } \\
\text { report a sense of } \\
\text { access to infinite } \\
\text { space }\end{array}$ \\
\hline Body & $\begin{array}{l}\text { Material, three- } \\
\text { dimensional }\end{array}$ & $\begin{array}{l}\text { Energy form or } \\
\text { subtle body; occu- } \\
\text { pies a location in } \\
\text { three-dimensional } \\
\text { space; form may } \\
\text { be none, spherical, } \\
\text { humanlike, or in- } \\
\text { substantial (smoky, } \\
\text { wispy) }\end{array}$ & $\begin{array}{l}\text { Energy form or sub- } \\
\text { tle body; occupies } \\
\text { a location in three- } \\
\text { dimensional space; } \\
\text { form may be none, } \\
\text { spherical, human- } \\
\text { like, or insubstantial } \\
\text { (smoky, wispy) }\end{array}$ \\
\hline $\begin{array}{l}\text { Physical } \\
\text { constraints }\end{array}$ & $\begin{array}{l}\text { Newtonian laws } \\
\text { of physics }\end{array}$ & $\begin{array}{l}\text { Exists in Newto- } \\
\text { nian world but not } \\
\text { subject to gravity } \\
\text { or physical means } \\
\text { of locomotion }\end{array}$ & $\begin{array}{l}\text { Exists in Newtonian } \\
\text { world but not sub- } \\
\text { ject to gravity or } \\
\text { physical means of } \\
\text { locomotion; can pass } \\
\text { through material } \\
\text { objects }\end{array}$ \\
\hline $\begin{array}{l}\text { Perceptual } \\
\text { inputs }\end{array}$ & Sensory, somatic & $\begin{array}{l}\text { Sensory field re- } \\
\text { duced to visual } \\
\text { and intuitive }\end{array}$ & $\begin{array}{l}\text { Senses heightened, } \\
\text { but largely visual } \\
\text { and auditory or } \\
\text { telepathic (sensory } \\
\text { impressions may } \\
\text { be analogous) }\end{array}$ \\
\hline
\end{tabular}

*From Carr (1993), Greyson (1985, 1991), Moody, 1975, 1977), and Ring (1980, 1984). 
both as an object and a former state, by the more complete afterdeath self. In the after-death mode, regression subjects experienced their deceased personality as a rather immature, unrefined version of themselves. They identified with the deceased personality to the extent of accepting it as a part of themselves formerly known subjectively yet now viewed objectively.

Accompanying this estrangement was a shift in point of view, which respondents likened to the vicariousness of an observer rather than being the actor in the thick of unfolding events. The after-death self was characterized by a lack of ego investment in the past-life personality, which pierced the defense mechanisms of the defunct persona. In the after-death mode, subjects could see their former self with great objectivity. Yet this unblinking assessment was not judgmental in a harsh way, but accepting of the deceased's foibles. The post-death self took full responsibility for having been what was now viewed as a rather pathetic person. Because this spontaneous feature of regression is so distinctive, several records are quoted to capture its fullness:

There's a sense of identity, a real core identity that isn't altered. I'm me, the result of what I learned in that life. The lessons become part of my identity, but . . . the sense of personality . . . is gone. There is an identity on a spiritual level, the identity of my mind, my consciousness in the spiritual way of things, a continuation, an accumulation of all the lives and all the lessons. I go from being this identity of a personality, this soldier [lying there], to this spiritual being who is not that limited soldier . . .but a bigger identity. (Subject 1)

It's almost like I'm looking at someone else. I'm no longer involved in that person. When I'm in the regression [personality], I'm experiencing everything that is going on. I'm talking about what I think, what I do. When I'm in that [after-death] state, I start automatically using the third person, what she did, what she felt . . . It's almost like I'm very disassociated from myself. (Subject 5)

I'm looking at the body as if it's a part of me, but it's not a part of me. It's separate .... I'm also a little more detached. I can look at [myself] as the one who froze to death, . . . the town drunk, and there I am. There's no judgment about it, it's just there I am. It doesn't make a big difference. (Subject 7)

It's almost like watching a close relative or a child make a mistake, and you think, gee, well, they could have done it differently, but that's the way they did it, so that's the way it is. (Subject 6)

It doesn't seem to be so much judgment [likel they did wrong, or they should have done this .... It's almost as if I'm looking at some 
of my students ... and thinking, they just didn't do it. So that's the kind of maternal feeling I have towards the [past-life self]. (Subject 4)

Although these assessments were characterized by acceptance, they were often accompanied by feelings of remorse or regret. The after-death self had a distinctly broader perspective on life than the regressed personality had had while it was alive, a feature that does not appear in the OBE phase of NDEs. In particular, the after-death self possessed wisdom concerning the "lessons" that might have been learned during the lifetime (unprompted by the therapist), and felt regret that the past-life personality had failed to make use of these opportunities, often expressed as having "wasted" the life:

What I came out with was that [the very thing] I was so afraid of was [exactly] what I was doing. The futility and the waste. The key lessons and the key pieces are smacking you in the face lafter death]. I've never gone through a review of my life, so to speak, but [I realize] everything that I was afraid of or avoided, I ended up not doing, and that [causes] all the regrets. If I'd just been more honest or open or just not afraid, I wouldn't have created that problem. I guess it's a life review, but not a life flashing in front of my eyes, but just ugh! (Subject 8 )

In some cases, there are feelings of remorse of what might have been, but it's really tempered with the feeling that that was what was to be in that life. What was, was, and what will be, will be. There is an opportunity to change. (Subject 4)

When it's over, you can look back, and all of a sudden everything is clear. You can see how you blew it. You're not hung up about what a pitiful person or life it was, but I always have the feeling that, gee, I wasted that life. I had a lot of chances, and I just wasted them. (Subject 9)

Often this remorse was tempered by the nature and quality of the past life. Residual emotions appeared to form the strongest connection between the after-death self and the past-life personality. Although all affect experienced by the after-death self seemed quite muted compared to that of the regressed personality when it was alive, the after-death self seemed bound by the emotional experience of the past life. All emotions but fear carried over from life beyond death:

My thinking about the [past-life personality] ... and the emotions that come up are related to the pain that person was feeling or the experiences they went through. Much of that has been grief in my experience, feeling a sense of loss for the loss of life that was wasted, or compassion for that person who was yourself and the pain they went through. Loss, grief, and compassion, and a sort of sense of 
love. It's strong, but slightly removed from a current experience of loss . . . . If . . . someone you know die[s], it has a current intensity. It's not that intense, but it's similar to watching a movie. If you watch . . . the whole story [about a] person, ... . when they die, then you feel that kind of intensity. (Subject 7)

It's a sense of awareness, of being aware in a complete way of what that life was about, ... . what things weren't connected right, what wasn't good in that life, but not in a judgmental sense . . . It's relatively flat emotionally ... That immediate after-death state has emotional content-regret, remorse, pain. Part of it is gone. Fear is gone, but sadness can be there for a variety of reasons, . . . loss of connection with loved ones, loss of opportunity, sense of waste, sadness about the way a life turns out. (Subject 2)

[In one regression, my life] was very peaceful, a life of love, yeah, no regret. This was a peaceful life, and it [was just] time to move on. So that state is very dependent on past-life personality. (Subject 5)

In addition to knowledge about the opportunities for learning presented to the past-life personality, after-death mentation was reported to be quick, clear, and unfettered by the constraints imposed by the past-life personality, especially ego defense mechanisms. Participants felt they tapped into a broader source of knowledge that was somehow intuitively apprehended:

I just seem to understand what was going on [during the past life] . . . I I just seem to have a lot more information available than I did [before]. (Subject 1)

My self in this state is now aware of something about the meaning of this life, the purpose [of it], the problems being worked through, the debts being paid, or things that I wasn't aware of when I was . . in the body. It's a different perspective than in the life . . . . Where it may have [been] baffling when you were going through these various experiences, now it has some resolution . . . . You're able to put things in context and gain some understanding of meaning. (Subject 4)

Immediate wisdom, uncluttered . . . by attachments, boundaries, fears, limitations . . . . Understanding or acknowledgment of the spiritual perfection that is so well masked in life. Immediate knowing without all the filters and garbage we put in the way. (Subject 8)

Compared to the regressed personality, after-death awareness was said to be free from physical, mental, and emotional constraint, even though it was still focused on the life that just ended. Subjects felt relatively peaceful because emotions were muted; fear and pain were gone. Table 2 contrasts aspects of self-identification during the past 
Table 2

Experience of Self During Death in Past-Life Regression and During the NDE Out-of-Body State

\begin{tabular}{|c|c|c|c|}
\hline & $\begin{array}{c}\text { Living } \\
\text { Regressed } \\
\text { Personality }\end{array}$ & $\begin{array}{c}\text { Regressed } \\
\text { Post-Death } \\
\text { Self }\end{array}$ & $\begin{array}{c}\text { NDE } \\
\text { Post-Death } \\
\text { Self }\end{array}$ \\
\hline $\begin{array}{l}\text { Self-identifi- } \\
\text { cation }\end{array}$ & $\begin{array}{l}\text { Identified with } \\
\text { regressed } \\
\text { personality }\end{array}$ & $\begin{array}{l}\text { Two selves; } \\
\text { after-death self } \\
\text { considers re- } \\
\text { gressed per- } \\
\text { sonality as a } \\
\text { lesser subper- } \\
\text { sonality }\end{array}$ & $\begin{array}{l}\text { Continuation of } \\
\text { same self after } \\
\text { death; after-death } \\
\text { self sometimes tries } \\
\text { to re-enter body as } \\
\text { old self, but may } \\
\text { also regard body } \\
\text { with some repug- } \\
\text { nance as a shadow } \\
\text { aspect of self }\end{array}$ \\
\hline Point of view & $\begin{array}{l}\text { Actor enmeshed } \\
\text { in here-and-now }\end{array}$ & $\begin{array}{l}\text { Assessor of } \\
\text { regressed per- } \\
\text { sonality }\end{array}$ & $\begin{array}{l}\text { Actor enmeshed } \\
\text { in here-and-now }\end{array}$ \\
\hline Context & $\begin{array}{l}\text { Immediate life } \\
\text { events }\end{array}$ & $\begin{array}{l}\text { Beyond and out- } \\
\text { side of biograph- } \\
\text { ical life; lessons } \\
\text { or opportunities } \\
\text { available given } \\
\text { the circumstances } \\
\text { of that life; sum- } \\
\text { mary or over- } \\
\text { arching view of } \\
\text { themes, few } \\
\text { specific acts }\end{array}$ & $\begin{array}{l}\text { Immediate life } \\
\text { events; during life } \\
\text { review, opportun- } \\
\text { ities are seen as } \\
\text { used or wasted, } \\
\text { but as specific } \\
\text { acts, from which } \\
\text { themes may be } \\
\text { deduced }\end{array}$ \\
\hline $\begin{array}{l}\text { Personality } \\
\text { traits }\end{array}$ & $\begin{array}{l}\text { Idiosyncratic; } \\
\text { often imma- } \\
\text { ture; actively } \\
\text { involved with } \\
\text { thoughts, feel- } \\
\text { ings, actions; } \\
\text { considerable } \\
\text { ego }\end{array}$ & $\begin{array}{l}\text { Detached intel- } \\
\text { lect; more ma- } \\
\text { ture than in life; } \\
\text { insightful; recep- } \\
\text { tively thinking } \\
\text { and feeling; self } \\
\text { but little ego }\end{array}$ & $\begin{array}{l}\text { Detached intellect; } \\
\text { same maturity as } \\
\text { in life; insightful; } \\
\text { receptively thinking } \\
\text { and feeling; vari- } \\
\text { ance in egocentric- } \\
\text { ity; some are still } \\
\text { emotionally at- } \\
\text { tached, disturbed } \\
\text { to be dead }\end{array}$ \\
\hline
\end{tabular}

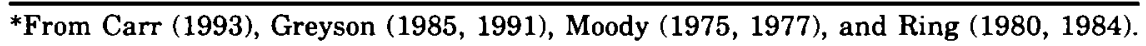


life, after the death of the "former" self, and the out-of-body stage of NDEs.

The transition from being in the body to the OBE in past-life regression was clearly marked by an increased psychological maturity and an increased cognitive ability, while emotionality and ego defenses decreased. The sense of knowledge, purpose, and meaning also shifted during the transition from life to death. Few of these changes are reported at this point in the NDE. Whereas past-life cognition is intuitive and insightful regarding the deceased self, NDE cognition is telepathically attuned to the thoughts and feelings of others (Moody, 1975, 1977; Ring, 1980, 1984). Moreover, during the life review of NDEs, survivors report awareness of opportunities seized or lost as they view specific events. But the past-life perspective is a global and thematic review of the entire life, an aggregate impression of the primary issues rather than a revisiting of specific incidents. This regression overview occurs in the out-of-body state, whereas the life review seems to occur at different phases of the near-death process.

Cognitive and affective aspects of past-life and NDE out-of-body stages are shown in Table 3.

\section{Discussion}

These findings confirm that consciousness was experienced quite differently after the death of the regressed personality, compared to the baseline state, as the purported previous biographical life events unfolded. Only some of these changes have direct parallels in the OBE phase of NDEs. The most similar dynamics concern the physical and spatiotemporal sensations of being out of the body after death. It is striking that NDE-naive regressed subjects spontaneously experienced the same spatiotemporality described by people who are clinically dead. Trauma, disease, drugs, and chemical changes associated with the dying brain, hypothetical causes postulated by various researchers to explain NDE phenomena (Broughton, 1991; Carr, 1982; Christopher, 1979; Rodabough, 1985; Siegel, 1977, 1980), are not obviously analogous to the physical state of healthy, living people undergoing past-life regression therapy.

Physiological parallels in neurological functioning between living subjects in trance and those with little or no measurable bioelectromagnetic brain functioning as measured by EEGs are extremely tenuous, given the present stage of research. Trance states are noted 
Table 3

Cognitive and Affective Aspects of Death in Past-Life Regression and in the NDE Out-of-Body State

\begin{tabular}{|c|c|c|c|}
\hline & $\begin{array}{c}\text { Living } \\
\text { Regressed } \\
\text { Personality }\end{array}$ & $\begin{array}{c}\text { Regressed } \\
\text { Post-Death } \\
\text { Self }\end{array}$ & $\begin{array}{c}\text { NDE } \\
\text { Post-Death } \\
\text { Self* }\end{array}$ \\
\hline $\begin{array}{l}\text { Prevalent } \\
\text { emotion on } \\
\text { being out of } \\
\text { body }\end{array}$ & $\begin{array}{l}\text { Fear; pain; } \\
\text { anger; sadness; } \\
\text { love (occasion- } \\
\text { ally) }\end{array}$ & $\begin{array}{l}\text { Peace; relief; } \\
\text { liberation; re- } \\
\text { sidual emotion }\end{array}$ & $\begin{array}{l}\text { Joy, euphoria; } \\
\text { peace; relief; some- } \\
\text { times confusion } \\
\text { and fear, accom- } \\
\text { panied by des- } \\
\text { perate attempts } \\
\text { to re-enter the } \\
\text { body; longing to } \\
\text { contact or com- } \\
\text { fort the living }\end{array}$ \\
\hline $\begin{array}{l}\text { Stimulus with } \\
\text { which emotions } \\
\text { are associated }\end{array}$ & $\begin{array}{l}\text { Survival of the } \\
\text { body; significant } \\
\text { others }\end{array}$ & $\begin{array}{l}\text { Freedom from the } \\
\text { body; significant } \\
\text { others; experiences } \\
\text { of the regressed } \\
\text { personality }\end{array}$ & $\begin{array}{l}\text { Freedom from the } \\
\text { body; significant } \\
\text { others }\end{array}$ \\
\hline Focus & $\begin{array}{l}\text { Here-and-now } \\
\text { life events }\end{array}$ & $\begin{array}{l}\text { Assessment of } \\
\text { life opportunities } \\
\text { presented to the } \\
\text { regressed person- } \\
\text { sonality }\end{array}$ & $\begin{array}{l}\text { Here-and-now } \\
\text { life events }\end{array}$ \\
\hline $\begin{array}{l}\text { Emotions asso- } \\
\text { ciated with } \\
\text { focus }\end{array}$ & $\begin{array}{l}\text { Appropriate or } \\
\text { inappropriate } \\
\text { feelings }\end{array}$ & $\begin{array}{l}\text { Acceptance; mild } \\
\text { feelings of regret }\end{array}$ & $\begin{array}{l}\text { Appropriate feel- } \\
\text { ings }\end{array}$ \\
\hline Cognition & $\begin{array}{l}\text { Similar to nor- } \\
\text { mal, waking } \\
\text { consciousness; } \\
\text { enmeshed in } \\
\text { life events; } \\
\text { colored by emo- } \\
\text { tional and egoic } \\
\text { loadings }\end{array}$ & $\begin{array}{l}\text { Comprehensive, } \\
\text { even omniscient } \\
\text { concerning past } \\
\text { life; intuitive; see } \\
\text { meaning and pur- } \\
\text { pose of the de- } \\
\text { ceased personality's } \\
\text { life unclouded by } \\
\text { egoic filters }\end{array}$ & $\begin{array}{l}\text { Telepathic concern- } \\
\text { ing others; height- } \\
\text { ened awareness and } \\
\text { clarity of here-and- } \\
\text { now; during life re- } \\
\text { view, the meaning } \\
\text { of specific oppor- } \\
\text { tunities becomes } \\
\text { clear }\end{array}$ \\
\hline
\end{tabular}

*From Carr (1993), Greyson (1985, 1991), Moody (1975, 1977), and Ring (1980, 1984). 
for more regular brain waves and greater right hemisphere involvement (Achterberg, 1994; Brown, 1986; Smith, 1984; Winkelman, 1986), neither of which are measurably present in NDEs. One highly speculative hypothesis that the Sylvian fissure of the right temporal lobe is the locus of certain aspects of the NDE (Morse and Perry, 1990, 1992; Saverdra-Aguilar and Gómez-Jeria, 1989) could tentatively be put forward as a link between these two states. Many difficulties exist with the Sylvian fissure argument for NDEs alone (Wade, 1996), but activity in this part of the brain might indeed contribute to the out-of-body experiences of healthy trance subjects. If it can be shown somehow that the Sylvian fissure is the last part of the brain to die, its neurological activity could perhaps be responsible for the similarities in phenomenology between "real" near-death experiences and those occurring in trance.

It seems likely that some kind of neurological shift creates the phenomenological changes from life to death during trance, notably the diminishment of emotions and ego defenses that occurs at the death of the past-life persona. It would appear that the baseline conscious state accesses messages from more parts of the brain than the after-death memory state, a subtle reflection of the gross changes seen in NDEs where the brain goes from measurable activity to none. The survival needs, intense emotions, and somatic sensations of the regressed personality suggest considerable lower brain and limbic system involvement while the after-death self seems to have subordinated or "lost" these neurological influences to a quasi-neocortical dominance over subjective awareness. The shift in the trance mode, however, cuts down on sensory inputs, while the NDE enhances them or adds an analogous form of telepathy or extrasensory perception not present in regressions.

If the other phenomenological similarities can be interpreted as analogous-that is, if the passage from life to death during a regression mimics the physiological passage from "real" life to death (Holden and MacHovec, 1993)-then the findings may be supportive of past-life recollections as true memories of a previous existence. The difficulties of "proving" past-lives to be true recollections are outside the scope of this paper, but research on the veridical re-creation of earlier somatic states impossible to mimic, such as the Babinski reflex (Raikov, 1980), and the retention of past-life wounds as birthmarks in children (Stevenson, 1975-80, 1980, 1987, 1997) suggest that earlier physiological states may be held in the body's memory. Mapping shifts in the body's electromagnetic fields, especially brain 
energy patterns, during past-life regression for comparison with biological death might illuminate troublesome issues in both areas.

On the other hand, the findings of greater psychological insight and clarity after death during regressions compared to NDEs tend to support the notion that the therapeutic experience may be metaphorical. The omniscience, wisdom, and broadened perspective displayed by the regressed post-death self is in marked contrast to the concern with immediate events displayed during the OBE portion of NDEs. Although the reduction in ego defensiveness is analogous to other "insight" experiences in psychotherapy, it has no direct experiential parallels in modalities using altered states alone, such as dreaming and holotropic breathwork. The post-death self's detached and expanded frame of reference seems to be matched only in modalities that incorporate both altered states and an "altered self," such as guided imagery or other techniques that access a different mode of being. In these modalities, the psychological construct popularly called the "higher self" functions as a hidden, wise inner resource that provides answers or insights to the ordinary self, a process revealing some dissociation and projection. Psychological theory suggests that this higher self may be a subpersonality, or a form of consciousness originating in the "silent" right hemisphere, which is disinhibited in altered state work (Beahrs, 1983; Hilgard, 1992; Siegel, 1977). Of course, this explanation returns to the physiological issues discussed above.

Such findings might tend to support the contention that near-death phenomena, including the otherworldly apparitions, are projections of the individual's psyche (Carr, 1993). Psychological projections, whether the regressed after-death self, the higher self, or spiritual figures encountered in the otherworldly phase of NDEs, may be selfconstructed illusions, as suggested by such varied sources as The $T i$ betan Book of the Dead (Evans-Wentz, 1960) and reductionistic authors like Ronald Siegel (1977), Ernest Hilgard (1992), and Ian Wilson (1982).

If the dissociation and depersonalization arguments put forward by Russell Noyes and Roy Kletti (1972; Noyes, 1980, 1981, 1982-3) based on life-threatening situations can truly be extended to survivors of clinical death-which is very questionable (Greyson, 1990; Morse and Perry, 1990) - they might provide a link between NDEs and the sense of an altered self experienced in past-life regression and other "higher self" modalities. Dissociation, the splitting of the persona into subpersonalities, often creates entities that act as pro- 
tectors, guides, or champions, as is commonly seen in the condition traditionally called multiple personality disorder and recently renamed dissociative identity disorder. Noyes credited the out-of-body experiences, life reviews, and otherworldly visions of the NDE with having an adaptive function in permitting the frightened, threatened ego to avoid knowledge of its own demise. Comparisons between the dissociation of pathological states, NDEs, and other altered states are common reductionist arguments (Wilson, 1982). While the basic dynamics of forming alternate sources of a sense of self may be the same, it is difficult to reconcile the clearly pathological examples with the mature insightfulness of the higher self known to transpersonal psychology, much less with the positive changes in mental health resulting from NDEs (Bauer, 1985; Morse and Perry, 1992; Sutherland, 1990). Nevertheless both NDE and regressed post-death experiences of self might benefit from comparison with pathological instances of dissociation, depersonalization, and "healthy" altered selves reported in the mystical and transpersonal literature, such as moksha (Suzuki, 1961) or Arthur Deikman's Observing Self (1969, 1982).

As indicated, this was only a pilot study, but it does provide a number of indicators for future research. At a minimum the reductionist argument that NDEs are the result of physical pathology in the brain is challenged by findings that a significant portion of the NDE phenomenology can occur in healthy, living humans. Nevertheless, the results still suggest that increased right-hemisphere activity, perhaps including the Sylvian fissure, might account for similarities among NDEs, regression, and other altered states. Arguments that NDEs are the result of disordered or wishful mental processes (Kurtz, 1985; Wilson, 1982; Zaleski, 1987) may also find some substantiation through the parallels to past-life regression therapy.

\section{References}

Achterberg, J. (1994). Healing images and symbols in nonordinary states of consciousness. ReVision 16(4), 148-156.

Bache, C. M. (1990). New lifecycles: Reincarnation and the web of life. New York, NY: Paragon House.

Bauer, M. (1985). Near-death experiences and attitude change. Anabiosis: The Journal of Near-Death Studies, 5(1), 39-47.

Beahrs, J. O. (1983). Co-consciousness: A common denominator in synopsis, multiple personality, and normalcy. American Journal of Clinical Hypnosis, 26, 100-113.

Broughton, R. S. (1991). Parapsychology: The controversial science. New York, NY: Ballantine. 
Brown, J. A. (1986). Relationships between phenomena of consciousness and interhemispheric brainwave patterns during nonordinary states of consciousness. Unpublished doctoral dissertation, Saybrook Institute, San Francisco, CA.

Carfaro, D. D. (1986). [The use of hypnoanalysis in sex therapy]. Revista Internazionale di Psicologia e Ipnosi, 27, 319-323.

Carr, C. (1993). Death and near-death: A comparison of Tibetan and Euro-American experiences. Journal of Transpersonal Psychology, 25, 59-110.

Carr, D. (1982). Pathophysiology of stress-induced limbic lobe dysfunction: A hypothesis for NDEs. Anabiosis: The Journal of Near-Death Studies, 2, 65-76.

Christie-Murray, D. (1981). Reincarnation: Ancient beliefs and modern evidence. Newton Abbot, England: David and Charles.

Christopher, M. (1979). Search for the soul: An insider's report on the continuing quest by psychics and scientists for evidence of life after death. New York, NY: Crowell.

Cladder, J. M. (1986). Past-life therapy with difficult phobics. Journal of Regression Therapy, 1(2), 81-85.

Deikman, A. J. (1969). Deautomatization and the mystic experience. In C. T. Tart (Ed.), Altered states of consciousness (pp. 23-43). New York, NY: Wiley.

Deikman, A. J. (1982). The observing self: Mysticism and psychotherapy. Boston, MA: Beacon.

Evans-Wentz, W. Y. (Ed.). (1960). The Tibetan book of the dead or the after-death experiences on the bardo plane, according to Lama Kazi Dawa-Samdup's English rendering. New York, NY: Oxford University Press.

Fiore, E. (1978). You have been here before: A psychologist looks at past lives. New York, NY: Ballantine.

Greyson, B. (1985). A typology of near-death experiences. American Journal of Psychiatry, 142, 967-969.

Greyson, B. (1990). Near-death encounters with and without near-death experiences: Comparative NDE scale profiles. Journal of Near-Death Studies, 8, 151-161.

Greyson, B. (1991). Encounters with death. In E. Bernstein (Ed.), Encyclopedia Britannica 1992 Medical and Health Annual (pp. 46-55). Chicago, IL: Encyclopedia Britannica.

Grof, S. (1985). Beyond the brain: Birth, death and transcendence in psychotherapy. Albany, NY: State University of New York.

Hilgard, E. R. (1992). Divided consciousness and dissociation. Consciousness and Cognition: An International Journal, 1(1), 16-31.

Holden, J. M., and MacHovec, R. (1993). Risk management in hypnotic recall of neardeath experiences. American Journal of Clinical Hypnosis(36), 38-46.

Hull, W. F. (1984). Prenatal oxygen deprivation, the source of birth trauma. Medical Hypnoanalysis 5(1), 7-16.

Kurtz, P. (Ed.). (1985). A skeptic's handbook of parapsychology. Buffalo, NY: Prometheus.

Marriott, J. (1984). Hypnotic regression and past lives therapy: Fantasy or reality? Australian Journal of Clinical Hypnotherapy and Hypnosis 5(2), 65-72.

Moody, R. A. (1975). Life after life. Covington, GA: Mockingbird Books.

Moody, R. A. (1977). Reflections on life after life. St. Simon's Island, GA: Mockingbird Books.

Morse, M., and Perry, P. (1990). Closer to the light: Learning from the near-death experiences of children. New York, NY: Villard.

Morse, M., and Perry, P. (1992). Thansformed by the light: The powerful effect of neardeath experiences on people's loves. New York, NY: Villard.

Nash, M. R. (1992). Hypnosis, psychopathology, and psychological regression. In E. Fromm, M. R. Nash (Eds.), Contemporary hypnosis research (pp. 149-169). New York, NY: Guilford.

Netherton, M., and Shiffrin, N. (1978). Past lives therapy. New York, NY: Morrow. 
Noyes, R. J. (1980). Attitude change following near-death experiences. Psychiatry, 43, 234-242.

Noyes, R. J. (1981). The encounter with life-threatening danger: Its nature and impact. Essence 5, 21-32.

Noyes, R. J. (1982-83). The human experience of death or, what can we learn from near-death experiences? Omega 13, 251-259.

Noyes, R., and Kletti, R. (1972). The experience of dying from falls, Omega, 3, 45-52.

Oppenheim, G. (1986). Who were you before you were you? Journal of Regression Therapy, 1(1), 20-27.

Raikov, V. L. (1980). Age regression to infancy by adult subjects in deep hypnosis. American Journal of Clinical Hypnosis, 22, 156-163.

Ring, K. (1980). Life at death: A scientific investigation of the near-death experience. New York, NY: Coward, McCann and Geoghegan.

Ring, K (1984). Heading toward omega: In search of the meaning of the near-death experience. New York, NY: Morrow.

Ring, K., and Cooper, S. (1997). Near-death and out-of-body experiences in the blind: A study of apparent eyeless vision. Journal of Near-Death Studies, 16, 101-147.

Ring, K., and Lawrence, M. (1993). Further evidence for verdical perception during near-death experiences. Journal of Near-Death Studies, 7, 205-222.

Rodabough, T. (1985). NDEs: Examination of the supporting data and alternative explanations. Death Studies, 9, 95-113.

Rogo, D. S. (1985). The search for yesterday: A critical examination of the evidence for reincarnation. Englewood Cliffs, NJ: Prentice Hall.

Saavedra-Aguilar, J. C., and Gómez-Jeria, J. S. (1989). A neurobiological model for near-death experiences. Journal of Near-Death Studies, 4, 107-123.

Sabom, M. (1982). Recollections of death: A medical investigation. New York, NY: Harper and Row.

Schlotterbeck, K. (1987). Living your past lives: The psychology of past-life regression. New York, NY: Ballantine.

Siegel, R. K. (1977, October). Hallucinations. Scientific American, pp. 132-140.

Siegel, R. K. (1980). The psychology of life after death. American Psychologist, 35 , 911-931.

Smith, A. (1984). The mind. New York, NY: Viking.

Stevenson, I. (1975-1980). Cases of the reincarnation type (Vols. 1-3). Charlottesville, VA: University Press of Virginia.

Stevenson, I. (1980). Twenty cases suggestive of reincarnation (rev. ed.). Charlottesville VA: University Press of Virginia.

Stevenson, I. (1987). Children who remember previous lives: A question of reincarnation. Charlottesville, VA: University Press of Virginia.

Stevenson, I. (1997). Reincarnation and biology: A contribution to the etiology of birthmarks and birth defects. Westport, CT: Praeger.

Sutherland, C. (1990). Changes in religious beliefs, attitudes, and practices following near-death experiences: An Australian study. Journal of Near-Death Studies, 9, 2131.

Suzuki, D. T. (1961). Essays in Zen Buddhism. New York, NY: Grove Press.

Tart, C. T. (1983). States of consciousness. El Cerrito, CA: Psychological Processes.

TenDam, H. (1990). Exploring reincarnation. London, England: Penguin.

Wade, J. (1996). Changes of mind: A holonomic theory of the evolution of consciousness. Albany, NY: State University of New York Press.

Wambach, H. (1978). Reliving past lives. New York, NY: Harper and Row.

Wambach, H. (1981). Life before life. New York, NY: Bantam.

Wambach, H. (1986). Past-life therapy: The experience of twenty-six therapists (C. Snow, Ed.). Journal of Regression Therapy, 1(2), 73-80.

Weiss, B. L. (1988). Many lives, many masters. New York, NY: Simon and Schuster. 
Wilson, I. (1982). All in the mind: Reincarnation, hypnotic regression, stigmata, mul. tiple personality, and other little understood powers of the mind. Garden City, NY: Doubleday.

Windelman, M. (1986). Trance states: A theoretical model and cross-cultural analysis. Ethos, 14(2), 174-203.

Woolger, R. J. (1987). Aspects of past-life bodywork: Understanding subtle energy fields, part 1: Theory. Journal of Regression Therapy, 2(1), 7-21.

Woolger, R. J. (1988). Other lives, other selves: A Jungian psychotherapist discovers past lives. New York, NY: Bantam.

Zaleski, C. (1987). Otherworld journeys: Accounts of near-death experience in medieval and modern times. New York, NY: Oxford University Press. 